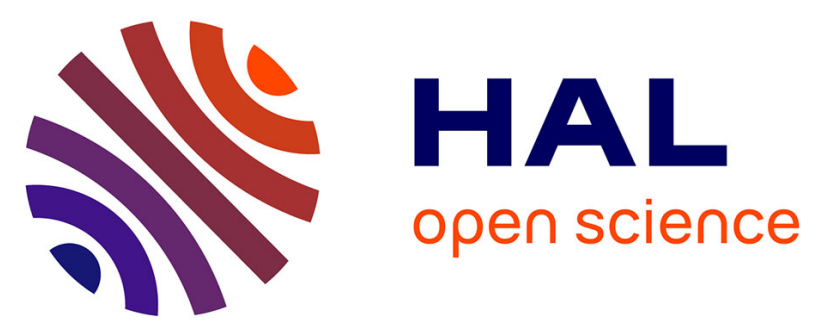

\title{
Study of a pulsed post-discharge plasma deposition process of APTES: synthesis of highly organic pp-APTES thin films with NH 2 functionalized polysilsesquioxane evidences
}

Simon Bulou, Elodie Lecoq, François Loyer, Gilles Frache, Thierry Fouquet, Magamou Gueye, Thierry Belmonte, Patrick Choquet

\section{To cite this version:}

Simon Bulou, Elodie Lecoq, François Loyer, Gilles Frache, Thierry Fouquet, et al.. Study of a pulsed post-discharge plasma deposition process of APTES: synthesis of highly organic pp-APTES thin films with NH 2 functionalized polysilsesquioxane evidences. Plasma Processes and Polymers, 2019, 16 (4), pp.1800177. 10.1002/ppap.201800177 . hal-02105341

\section{HAL Id: hal-02105341 \\ https://hal.univ-lorraine.fr/hal-02105341}

Submitted on 19 Nov 2020

HAL is a multi-disciplinary open access archive for the deposit and dissemination of scientific research documents, whether they are published or not. The documents may come from teaching and research institutions in France or abroad, or from public or private research centers.
L'archive ouverte pluridisciplinaire HAL, est destinée au dépôt et à la diffusion de documents scientifiques de niveau recherche, publiés ou non, émanant des établissements d'enseignement et de recherche français ou étrangers, des laboratoires publics ou privés. 


\title{
Study of a pulsed post-discharge plasma deposition process of APTES: synthesis of highly organic pp-APTES thin films with $\mathrm{NH}_{2}$ functionalized polysilsesquioxane evidences
}

Simon Bulou ${ }^{1}$, Elodie Lecoq ${ }^{1}$, François Loyer $^{1}$, Gilles Frache ${ }^{1}$, Thierry Fouquet ${ }^{1}$, Magamou Gueye $^{2}$, Thierry Belmonte ${ }^{2}$, Patrick Choquet ${ }^{1}$

${ }^{1}$ MRT Department, Luxembourg Institute of Science and Technology, 5 avenue des HautsFourneaux, L-4362 Esch/Alzette, Luxembourg

${ }^{2}$ Institut Jean Lamour, UMR CNRS 7198, Université de Lorraine, NANCY F-54011, France

\section{Keywords}

microwave discharges, plasma-enhanced chemical vapour deposition (PECVD), plasma polymerization, pulsed discharges, remote plasma processes

\begin{abstract}
This article reports the use of pulsed remote $\mathrm{Ar}-\mathrm{O}_{2}$ microwave plasma assisted chemical vapor deposition with an $-\mathrm{NH}_{2}$ containing organosilicon precursor ((3Aminopropyl)triethoxysilane: APTES). It is shown that modifying the plasma pulses duration (ton) and the plasma off duration (toff) allows to finely tune the deposited layer composition. In addition, the results of this work demonstrate that an important film growth occurs during toff, which results in an increased $-\mathrm{NH}_{2}$ density. Besides, high resolution MALDIORBITRAP Mass spectrometry analysis clearly points out that APTES oligomers up to eight base units, including silsesquioxanes (cages), and cyclosiloxanes (rings) molecules with intact $-\mathrm{NH}_{2}$ groups are embedded into the as grown pp-APTES thin film.
\end{abstract}




\section{INTRODUCTION}

Plasma polymers (pp) are of high interest as they can be deposited on a wide range of materials and synthesised from precursors that are not polymerisable by conventionnal approaches. In addition, polymeric thin films deposited by plasma assisted chemical vapor deposition (PACVD) method can provide pinhole-free thin films with a high adhesion to the substrate and a well controlled deposition rate even for very low thicknesses. They differ from conventionnal polymers as they usually exhibit irregular three-dimensional cross-linked structures instead of chains of repeated monomer units. Plasma polymer deposition can thus provide, depending on the precursor used, new surface features to a material without altering its bulk properties. One of the actual axes is the deposition of versatile reactive thin films for subsequent functionalizations.[1-4] Reactive thin films are layers that possess on their surface high density of reactive functional groups (such as carboxyl, $[3,4]$ amino,[3,5] hydroxyl,[6] or epoxy groups[1,7]) that can be used for subsequent functionalisation. For example, these layers can be used to promote adhesion or to immobilize bio-molecules of interest.[1,2,5] For this last application, research, and development studies show that these immobilized biomolecules can provide surfaces with drastically new chemical or physical properties. The soughtafter applications are thus very large and cover the field of new smart surfaces, which exploits size effects at the nanometre scale (catalytic, anti-bacteria, depollution,[1,2] lubricating, anti-fouling,[1] anti-fingerprint, self-healing corrosion protection,...)

To define such surface properties, one frequently-adopted method consists in depositing on a substrate, an intermediate reactive thin film in order to graft molecules of interest in a subsequent step.[1,2,4,8-13] Indeed, plasma processes have the advantage, compared to other surface modification techniques, of providing an effective way to activate surfaces by modifying the stoichiometry of their native oxide/hydroxide layer, directly followed by the chemical deposition of stable grafted groups at low temperature. The understanding of the different steps of the growth mechanisms of these functionalized chemical layers is still necessary and is extremely important to further control the functional group density and, consequently, to optimize their subsequent bonding with natural/synthesized biomolecules such as peptides and proteins.

Among the different reactive functional groups that can compose this intermediate layer, primary amines $\left(-\mathrm{NH}_{2}\right)$ are interesting owing to their high reactivity.[8,10,12,14,15] Indeed, $-\mathrm{NH}_{2}$ rich thin films are already known to immobilize bioactive molecules, $[8,16]$ improve implants biocompatibility and enhance chemical adhesion.[5,17-19] Among the 
various processes that enable deposition of $\mathrm{NH}_{2}$-rich thin films, PACVD, also called plasma polymerization, can lead to conformal and adherent amino containing layers.[9-12,15,20-33]

With this process, an organic precursor (monomer) containing an $-\mathrm{NH}_{2}$ group is activated by a plasma, that is, turned into a radical. The radicals then react and condense on a substrate thus leading to the thin film growth.[34] Nevertheless, $\mathrm{NH}_{2}$ moieties being highly reactive, it readily reacts with the plasma. Thus its incorporation in the film is still a matter of concern nowadays.

Different monomers have been already reported to synthesize amino containing thin layers. Among them, (3-Aminopropyl)triethoxysilane (APTES) is an aminoalkoxysilane that is known to achieve dense and adherent coatings.[8,11,13,14,16,28,31,32,35-38] It is widely used in sol-gel methods as it allows the deposition of amino-rich layers.[8,13,16,36,37] Compared to other $-\mathrm{NH}_{2}$ containing precursors, this aminosilane can provide a siloxane backbone that can provide dense silica-like layers that are known to be highly adherent on metallic surfaces, resistant to delamination and act as a barrier against diffusion. Furthermore, it is nontoxic and relatively cheap. The pp-APTES deposition using continuous wave (CW) PACVD or pulsed plasma PACVD has already been investigated by several authors.[11,39,40] However, the publications related to the synthesis of functional thin films with these plasma deposition processes report some limitations and more specifically, when reactive thin films with high density of functional chemical groups are expected. This can be explained by calculating the bond dissociation energy of the molecule by density functional theory (DFT). Indeed, if the $\mathrm{Si}-\mathrm{O}$ bonds are the most stable (i.e. $5.0 \mathrm{eV}$ ), the amine-bearing carbon chain is undoublty the weakest (i.e., down to $3.1 \mathrm{eV}$ ) and therefore more prone to fragment when submitted to highly energetic plasma (Figure 1). In order to retain as much amine groups as possible, it appears essential to use soft deposition methods such as, remote plasma PACVD (RP-PACVD) or plasma initiated CVD (PiCVD).[41,42]

Indeed, in order to keep the functional group unaltered, remote plasma (RP) (or postdischarge) PACVD, is usually preferred to direct plasma (DP) deposition where sufficiently energetic electrons can dissociate indistinctly any chemical bond of the precursor.

In RP-PACVD processes, the plasma generation and the thin film growth occur in two different areas spatially separated, called discharge chamber, and deposition chamber, respectively.[5,24,35,43-50] In the discharge chamber, the plasma is generated using non condensable gas whereas charged species are confined. Thank to the gas flow and/or a gradient of pressure, these neutral plasma species are flown in the deposition chamber and can be mixed with a chemical precursor. Precursors and reactive plasma species then interact 
leading to the thin film growth. This RP-PACVD process thus offers several advantages compared to DP -PACVD processes: (1) with this geometrical configuration, it is possible to limit the interactions of the chemical precursor with the high energetic species of the plasma (electrons, ions, UV) and, consequently, minimize its fragmentation; (2) the deposition mechanism can be mainly controlled by the interactions between neutral reactive plasma species and precursor molecules which allows to get a milder degradation; (3) the bombardment of the substrate by charged particles (ions) is negligeable and largely reduce their possible damage on the growing surface.

Nevertheless, some previous works based on the use of RP-PACVD have illustrated the difficulty to keep primary amine functional groups with such a process.[35,45,50] Indeed, the primary amine in APTES easily reacts with post-discharge active species, leading to relatively low amine density in the deposited plasma polymers compared to sol-gel methods.[35,36]

Another strategy used by different researchers to allow a better retention of the initial structure of the precursor is the use of a pulsed plasma.[9,15,20-23,25-27,51-54] Indeed, in continuous wave $(\mathrm{CW})$ direct plasma deposition, the injected monomer and the substrate are continuously exposed to UV and ion bombardment. This increase the monomer depletion, the cross-link density as well the dangling bond density in the film. Using pulsed plasma (sequences of plasma on times and plasma off times) allows to decrease the mean power injected in the discharge, as well as the flux of highly energetic species (UV, ions) that are detrimental for the integrity of the functional group bearing precursors. In addition, a very interesting feature of pulsed PACVD process is that, during plasma off times, reactions between long life plasma species, monomer molecules and radicals, can lead to the growth of the plasma polymer by mean of more "conventional" chemical reactions.[34,55-57] For all these reasons, the use of pulsed plasma for the synthesis of functional coatings usually leads to less cross-linked structure and higher density of reactive groups.[20,22,25,52,53,56] This strategy has been widely studied using polymerizable monomers, that is, unsaturated molecules (that possess double bonds or rings (acrylyc, vynylic, ...)).[15,20,21,23,25$27,29,41,42,55,56,58]$ As an example, in the case of pp deposition of amine containing thin films, pulsed plasma PACVD of allylamine has been widely studied and shows it superiority in terms of $-\mathrm{NH}_{2}$ groups incorporation compared to CW PECVD.[9,10,12,15,20,2427,29,33,59,60] Nevertheless, because of its accute tocixity, there is an interest in developing deposition process that use an alternative and non toxic $-\mathrm{NH}_{2}$ containing precursor, such as APTES. 
In the following work, we investigate the possibility of using simultaneously pulsed and remote plasma (pulsed RPPACVD) in order to favorise a very soft plasma polymerization process and thus promoting the growth of organic, highly ordered and $\mathrm{NH}_{2}$ containing thin film using APTES as precursor. The aim is to take advantages of both pulsed and remote PACVD processes in terms of mild precursor depletion, off times deposition and largely reduced density of plasma species bombardment on the substrate. The deposition of plasma polymers using pulsed remote plasma has been rarely studied in the litterature.[24,34,48] It thus appears interesting to investigate this strategy for the plasma polymerization of precursor containing fragile reactive groups such as primary amine $\left(-\mathrm{NH}_{2}\right)$. More particularly for this study, it has been chosen to study the deposition of pp- APTES thin film with active species generated by a microwave afterglow pulsed at very low frequency. The influence of both the on-time (ton) and off-time (toff) periods using this pulsed microwave post-dicharge with $\mathrm{Ar} / \mathrm{O}_{2}$ gas mixtures is investigated. Different deposition conditions are tested and their impacts in term of deposition rate, atomic composition, molecular structure, and primary ($\mathrm{NH}_{2}$ ) amine density are studied.

\section{EXPERIMENTAL SECTION}

Plasma-polymerized APTES coatings were deposited on both silicon ((100) surface orientation, intrinsic, $350 \mu \mathrm{m}$ thickness, double side polished) and aluminum samples. The experimental setup is depicted in Figure 2 and is very similar to the one used previously in a former article.[35] It is briefly summarized hereafter.

The discharge reactor was made of a $5 \mathrm{~mm}$ inner diameter quartz tube. The gas mixture $\left(\mathrm{Ar}, \mathrm{O}_{2}\right)$ was introduced into this tube by means of mass flow controllers. The total gas flow rate passing through the discharge tube was set at $500 \mathrm{sccm}$ (standard cubic centimeter per minute) (i.e., $490 \mathrm{sccm} \mathrm{Ar}+10 \mathrm{sccm} \mathrm{O}$ ). The discharge tube was inserted into a microwave Surfaguide wave launcher (Surfatron ${ }^{\circledR}$, SAIREM®) connected to a GMP 300 KD microwave generator.

The plasma was ignited in the discharge tube and the generated reactive species flowed out into a second reaction tube where the substrate holder is located. The vapor in equilibrium above the liquid APTES monomer was carried to the second tube by means of a bubbling system thanks to an Argon flow of $500 \mathrm{sccm}$. The bubbler was assumed to be at constant atmospheric pressure and ambient temperature $(293 \mathrm{~K})$. The vapor pressure of APTES is about $5 \times 10^{-2} \mathrm{mbar}$, the APTES flow rate being then equal to $0.025 \mathrm{sccm}$. 
The APTES vapor mixes with active species coming from the discharge tube, produces radicals that react on the substrate surface. The process pressure was measured in the deposition tube by means of a Pirani gauge and was adjusted between 5 and 10 mbar thanks to a throttle valve. The originality of this work lies in the use of a pulsed microwave far afterglow discharge. The underlying idea is to add new parameters, the frequency and the duty cycle, to better control the dissociation of the monomer. To limit the complexity of this work and favors the potential deposition during plasma off-times, we opted for long off-times, that is, several milliseconds. The applied microwave power was controlled by an external low-frequency generator delivering square waves. The peak power during the ton period was set for all deposition conditions at $300 \mathrm{~W}$. No power was dissipated during the toff period. The rising and falling times were respectively lower than $4 \mathrm{~ms}$ and $2 \mathrm{~ms}$. Compared to ton and toff values, they are considered as negligible.

The deposition rate of the film was evaluated by measuring the mass increase before and after deposition as a function of time. First, the Si substrate before deposition was weighed using a ME-36S microbalance (Sartorius). Considering the Si bulk density and thickness of the wafer used as substrate, the "coatable" surface was determined. The coated substrate was then weighed after deposition. The mass increase corresponds to the deposited pp-APTES. It was used to calculate a deposition rate expressed in nanograms per square meter and per minute of deposition $\left(\mathrm{ng} / \mathrm{m}^{2} / \mathrm{min}\right)$.

Coatings IR absorption spectra were recorded on a FTIR Bruker Hyperion 2000 in transmission mode. In order to have comparable FTIR spectra, the deposition time were adjusted in order to get coating of thickness of $150+/-10 \mathrm{~nm}$ for all the investigated deposition conditions. AFM Surface characterizations of the films were achieved using a Molecular Imaging Pico in intermittent (tapping) mode on $5 * 5 \mu \mathrm{m}$ squares (not shown here). For all experimental conditions explored in the following, the deposited thin films surfaces appear smooth with $\mathrm{Sa}$ and $\mathrm{Sq}(\mathrm{Sa}=$ arithmetical mean height; $\mathrm{Sq}=$ Root mean square height $)$ in the range of 0.7 and $1.8 \mathrm{~nm}$, respectively.

XPS analyses were realized with a Kratos Axis-Ultra instrument using a monochromatic Al Ka X-ray source $(\mathrm{h} v=1486.6 \mathrm{eV}$ ) at pass energy of $20 \mathrm{eV}$. Charge calibration was achieved by fixing the binding energy of the aliphatic carbon at $285 \mathrm{eV}$. The XPS spectra were then fitted by CasaXPS® software.

Density function theory (DFT) calculations were performed using the 4.0.1 orca program suite.[61] The hybrid functional B3LYP was used for every calculation along with Ahlrichs' basis set def2-TZVP and Weighend's auxiliary basis set def2/J.[62,63] The 
numerical chain of sphere approximation RIJCOSX and the dispersion correction D3 were also applied in any instance.[64,65] A geometric counterpoise scheme gCP(DFT/TZ) was used to correct for the basis set superposition error (BSSE) in the energy calculations.[66] An analytical frequency optimization followed every geometrical optimization to ensure the calculation reached the minimal of energy. No imaginary mode of vibration was detected. The bond dissociation energies were calculated using a previously described method.[41]

\section{RESULTS AND DISCUSSION}

\subsection{Ar $-\mathrm{O}_{2}$ pulsed plasma: Impact of frequency and duty cycle}

In a former publication, we studied the influence of the gaseous mixture on thin film composition for a continuous microwave excitation with a $\mathrm{N}_{2}$ discharge power of $200 \mathrm{~W}$.[35] It was concluded that $\mathrm{N}_{2}$ plasma does not allow to obtain amino-rich thin films. This behavior is believed to be related to the high reactivity of the $\mathrm{N}_{2}$ plasma, which provides a high flow of reactive species responsible for a strong depletion of the monomer. Moreover, the continuous plasma excitation brings a continuous flow of reactive plasma species onto the on-growing thin film, which further decreases its organic content and favors the deposition of a highly crosslinked plasma polymer.

Thus, in order to decrease the amount of plasma reactive species and thus to increase the amine content in the film, we chose to work with a pulsed $\mathrm{Ar}-\mathrm{O}_{2}$ plasma mixture with $2 \%$ of $\mathrm{O}_{2}\left(490 \mathrm{sccm} \mathrm{Ar}+10 \mathrm{sccm} \mathrm{O}_{2}\right)$. This mixture was used for all the results that are presented in this paper.

Figure 3 clearly shows the major impact of the pulsed $\mathrm{Ar}-\mathrm{O}_{2}$ plasma compared to a continuous $\mathrm{Ar}-\mathrm{O}_{2}$ plasma on the molecular structure of the film. A constant frequency of 10 $\mathrm{Hz}$ was kept in all experiments but the duty cycle was varied from $100 \%\left(t_{o n}=100 \mathrm{~ms}, t_{\text {off }}=0\right.$ $\mathrm{ms}$, that is, a CW plasma) to $10 \%$. As expected, the duty cycle does strongly influence the film's composition. Decreasing the duty cycle (i.e., reducing ton and increasing toff) leads to a decrease in the $\mathrm{C}=\mathrm{O}$ (carboxyl at $1720 \mathrm{~cm}^{-1}$; amide at $1680 \mathrm{~cm}^{-1}$ ) and $\mathrm{C}=\mathrm{N}\left(1660 \mathrm{~cm}^{-1}\right.$ ) absorption peaks and to an increase in the $-\mathrm{NH}_{2}$ absorption peak, in accordance with the amine-bearing carbon chain being the weakest to fragmentation in the molecule.

In the following section, the influence of the frequency, the duty cycle, $t_{\text {on }}$ and $t_{\text {off }}$ is investigated thoroughly.

Figure 4 presents the evolution of the deposition rate as determined from the mass variation as a function of the duty cycle (from 5 to 100\%) at 2 different frequencies: $10 \mathrm{~Hz}$ 
and $50 \mathrm{~Hz}$. At $50 \mathrm{~Hz}$, there is no influence of the duty cycle on the deposition rate (nearly constant). On the contrary, this latter parameter is strongly influenced by the duty cycle when the deposition is performed at $10 \mathrm{~Hz}$. At this stage, these results are complex to interpret because any change of the duty cycle changes not only the plasma on $\left(t_{o n}\right)$ but also the plasma off $\left(t_{o f f}\right)$ times. Nevertheless, these results show undoubtedly that deposition occurs both during the plasma-on and the plasma-off periods. This behavior has also been noticed by other authors working with unsaturated organic precursors and pulsed direct PACVD processes.[34,57] It has also been observed, whereas more rarely, when using organosilicon precursor.[55,67,68]

In order to improve our understanding of the growth mechanism, the following study was devoted to the influence of ton and toff.

\section{2. $\mathrm{Ar}-\mathrm{O}_{2}$ pulsed plasma: Influence of $t_{o n}$}

The influence of ton was evaluated by varying the value of this parameter within the range [25-400 ms]. This set of experiments was designed to get a better understanding of the growth mechanism during the on-time.

Table 1 depicts the main experimental parameters corresponding to the different deposition conditions.

The parameter toff was kept constant, equal to $200 \mathrm{~ms}$. This value roughly corresponds to the residence time of a gaseous molecule in the deposition tube. This value of toff was chosen to ensure that reactive plasma species from a given plasma pulse do not interact with species from the previous plasma pulse. In other words, using $t_{\text {off }}>200 \mathrm{~ms}$ ensures that coatings are made of stacked layers corresponding to successive plasma pulses with renewed gas mixtures. The total deposition duration, including $t_{\text {on }}$ and $t_{\text {off }}$, are adjusted for the different experiments in order to lead to a deposition thickness equal to $150+/-10 \mathrm{~nm}$.

Figure 5 presents the average mass of pp-APTES deposited per pulse (i.e., $t_{\text {on }}+t_{\text {off }}$ ) as a function of ton.

Unsurprisingly, this figure emphasizes that the weight gain of the layer (in $\mathrm{ng} \mathrm{mm}^{-2}$ ) deposited by pulse increases regularly with ton, almost linearly until $100 \mathrm{~ms}$. In other words, the deposited mass of the coating per pulse is proportional to the duration of plasma pulses. Interestingly, it can be observed that this deposition rate shifts from a linear behavior for ton $>100 \mathrm{~ms}$.

In addition, plotting the different average masses per unit area divided by ton brings complementary comments. Indeed, if we assume that the final coating is the same in 
composition and density regardless of the value of $t_{o n}$, then, the average deposition rate should be the same. Instead, Figure 6 clearly shows that the longer $t_{o n}$ is, the lower the deposition rate.

It can be explained as follows: first, the surface structure and chemistry of the layer changes during the plasma $t_{o n}$ and consequently the chemical interactions of the active plasma species are different. Second, a highest fragmentation of the APTES molecules when $t_{\text {on }}$ increases, leads to a lower deposition rate.

The atomic composition determined by XPS (Table 2) gives clues on the effect produced by a change of ton.

One can clearly see that for the longest ton, the $\mathrm{C}$ at.\% is divided by a factor of four while the $\mathrm{O}$ at.\% almost doubles when ton increases from 25 to $400 \mathrm{~ms}$. Besides, the Si at.\% slightly increases whereas the $\mathrm{N}$ at.\% is almost constant. This clearly demonstrates that $t_{o n}$ does not only change the deposition rate but also opens up the possibility to tune the inorganic/organic chemical character of the coatings. A long $t_{\text {on }}$ leads to higher chemical etching of the organic part of APTES, thus inducing a less organic film. One can clearly see in Figure 7, the impact of increasing $t_{o n}$ on the proportion of the organic part of the deposited film. Indeed, the $\mathrm{CH}_{\mathrm{x}}$ absorption peaks $\left(2800-3000 \mathrm{~cm}^{-1}\right)$ that can be clearly observed for $t_{\text {on }}$ $=25 \mathrm{~ms}$, are strongly reduced for $t_{o n}=100 \mathrm{~ms}$ and they totally disappear for $t_{o n}>200 \mathrm{~ms}$. On the contrary, $\mathrm{OH}$ absorption peaks gradually appear when ton increases.

This clearly indicates that the deposition gradually changes from an organic coating to an inorganic coating. In the range $\left[1200-1800 \mathrm{~cm}^{-1}\right]$, the increase in ton leads to a rise of the $\mathrm{C}=\mathrm{O}$ absorption peaks corresponding to amides $\left(1690 \mathrm{~cm}^{-1}\right)$ and carboxylic acids $(1720$ $\left.\mathrm{cm}^{-1}\right)$. A strong increase in the $\mathrm{C}=\mathrm{N}$ absorption peaks $\left(1620 \mathrm{~cm}^{-1}\right)$ is also observed. These evolutions indicate a progressive degradation of the initial molecular structure of the monomer. The evolution of the $-\mathrm{NH}_{2}$ absorption peak $\left(1550 \mathrm{~cm}^{-1}\right)$ is not so clear, but the primary amine group always exhibits a low intensity, whatever ton.

This is very likely because of the chemical reactions induced by plasma activated species (such as $\mathrm{O}_{2}{ }^{*}$, atomic $\mathrm{O}, \ldots$ ) contained in the plasma afterglow and transferred into the deposition area. These species, if they do not react with a monomer molecule in the gas phase, could impact, and react with the growing thin film. These reactions could lead to the break of atomic bonds and to a rearrangement of thin film bonding, thus inducing a higher degree of cross-linking. This effect would thus be more pronounced for the weakest bonds, that is, in case of pp-APTES, the amine-bearing carbon chain, thus progressively leading to aminedeficient inorganic $\mathrm{SiO}_{\mathrm{x}}$ layers as the ton increases. This effect is much more pronounced for 
long ton than for short ones. According to these results, it seems interesting in order to have a better control of the structure and to avoid undesired thin film etching of the coating to use short $t_{o n}$.

\subsection{Ar $-\mathrm{O}_{2}$ pulsed plasma: Influence of $t_{\text {off }}$}

The study of $t_{o n}$ 's influence points out that short $t_{o n}$ favor the retention of the APTES molecular structure in the deposited thin film. However, this first study does not give any information about the film growth during $t_{\text {off. }}$. It does not give either any information on the importance of the contribution of post-discharge processes to the plasma processes. The following section focuses on the influence of toff on the deposition rate. The objective is (1) to determine the contribution to the layer's growth during toff at a fixed $t_{\text {on }}$ and (2) how a change of toff affects the molecular structure of the deposited film. In this experimental section, a constant ton value of $50 \mathrm{~ms}$ was chosen. The influence of $t_{\text {off }}$ from $10 \mathrm{~ms}$ up to 400 ms has been studied. The corresponding experimental parameters are summarized in Table 3 .

Figure 8 plots the deposited mass per pulse (i.e., for one period $\left.\left(t_{o n}+t_{\text {off }}\right)\right)$ as a function of $\left(t_{o n}+t_{o f f}\right)$, for a constant $t_{o n}=50 \mathrm{~ms}$. It exhibits first an almost linear increase of the mass deposited per pulse, up to $t_{\text {off }}=100 \mathrm{~ms}$. Then, for $t_{\text {off }}>100 \mathrm{~ms}$, this mass rate remains constant.

This statement proves without any ambiguity that a contribution to the thin film growth must be associated with the off-time period. Furthermore, as the mass gain is linear versus time, the deposition rate during the off-time period is roughly constant up to $\approx 100 \mathrm{~ms}$. Besides, the mass deposited per pulse increases by a factor of three when $t_{\text {off }}$ increases from $10 \mathrm{~ms}$ to $100 \mathrm{~ms}$.

For $t_{\text {off }}>150 \mathrm{~ms}$, the deposited mass per cycle $\left(t_{o n}+t_{\text {off }}\right)$ remains constant, indicating there is no more deposition after $150 \mathrm{~ms}$ during off time period. It is worth noticing that the maximum mass gained per pulse is reached for $t_{o n}+t_{\text {off }}=150-200 \mathrm{~ms}$. This time is very close to the residence time $t_{\text {residence time }}=200 \mathrm{~ms}$ corresponding to the calculated residence time of a gaseous molecule to go from the entrance of the deposition tube to its exit.

It is possible to evaluate the mass of the coating deposited during the $t_{\text {on }}$ of $50 \mathrm{~ms}$. If we extrapolate the deposition curve down to $t_{\text {off }}=0 \mathrm{~ms}$ (i.e., $t_{\text {on }}+t_{\text {off }}=50 \mathrm{~ms}$ ), the mass deposited is $0.056 \mathrm{ng} / \mathrm{mm}^{2} /$ pulse. We can reasonably assume that this deposited mass during ton is equal independently of the $t_{\text {off }}$, thus, we could thus subtract this value to the mass deposited per pulse to have an approximation of mass deposited during $t_{\text {off }}$ (cf. Figure 9). 
Figure 9 shows that for $t_{\text {off }}>100 \mathrm{~ms}$, the mass deposited during $t_{\text {off }}$ is about 0.12 $\mathrm{ng} / \mathrm{mm}^{2} /$ pulse, which is about $65 \%$ of the total mass depositing rate. The mass deposited during toff represents thus a major part of the total mass deposited. The deposition during toff is much likely due to adsorption mechanisms. Among these, one can hypothesis the physisorption of APTES molecules followed by a chemistry conversion controlled by the reactive species coming from the remote plasma and also possible various chemisorption reactions of these molecules with dangling bonds and/or reactive groups on the topmost surface after plasma-on. One can also assume that it exists significant amount of condensation reaction of APTES molecules on the topmost surface, between ethoxy groups of gaseous APTES molecules and silanol groups of the film, similarly as APTES polymerization via solgel process. The latest reaction can explain the creation of siloxane bonds and the formation of APTES oligomers (cf. section 3.4).

Table 4 presents the atomic composition determined by XPS of the pp-APTES thin films as a function of $t_{\text {off }}$.

Results reported in table four show that by increasing $t_{\text {off }}$ during the pulse cycle, more organic thin films can be synthetized. Indeed, with $t_{\text {off }}$ varying from 10 to $200 \mathrm{~ms}$, the C content strongly increases from 8 at. $\%$ to 41 at. $\%$ while Si and O decrease from 29 at.\% to 21 at. $\%$ and from 50 at.\% to 30.5 at.\%, respectively. Besides, the $\mathrm{N}$ content strongly increases as $t_{\text {off }}$ goes from 10 to $50 \mathrm{~ms}$, but for $t_{\text {off }}>50 \mathrm{~ms}$, it stays constant, equal to $7.5 \%$. The $\mathrm{Si} / \mathrm{N}$ ratio (which is equal to one in the case of sol-gel APTES thin film with one amino-group on each silicon atom) decreases from $\mathrm{Si} / \mathrm{N}=12$ to $\mathrm{Si} / \mathrm{N}=3$ as $t_{\text {off }}$ increases from $10 \mathrm{~ms}$ to $200 \mathrm{~ms}$, indicating a much lower monomer depletion.

The benefit on the molecular structure with increasing $t_{\text {off }}$ is clearly seen when comparing FTIR spectra thin films presented in Figure 10.

While for $t_{\text {off }}=10 \mathrm{~ms}$, no methyl groups are observed, their concentration progressively increases with toff. Meanwhile, the wide absorbing band from 2800 to 3600 $\mathrm{cm}^{-1}$, corresponding to $\mathrm{OH}$ groups, strongly decreases. The origin of this band is probably due to two reasons: first, oxygen reactive species can react with methyl groups and especially $\mathrm{H}$ atoms to form $\mathrm{OH}$ groups during the deposition and second, it could also be due to post deposition-adsorption as $\mathrm{SiO}_{\mathrm{x}}$ films are known to absorb a high $\mathrm{H}_{2} \mathrm{O}$ quantity.

FTIR spectra between $1200 \mathrm{~cm}^{-1}$ and $2200 \mathrm{~cm}^{-1}$ points out the less reticulated structure of the films (absorption peaks exhibit smaller width at half maximum) obtained at long $t_{\text {off }}$, as well as more visible $-\mathrm{NH}_{2}$ group absorption peak. Also FTIR results are consistent with mass deposition results as the spectra are quite similar for $t_{\text {off }}>100 \mathrm{~ms}$. In addition, the 
$-\mathrm{NH}_{2}$ absorption peak seems identical in shape and intensity for thin films deposited for $t_{\text {off }}>$ $50 \mathrm{~ms}$. This result is in agreement with XPS results, which pointed out that $\mathrm{N}$ at.\% is identical for $t_{\text {off }}>50 \mathrm{~ms}$. This result, thus, suggests that a significant part of $\mathrm{N}$ atoms belong to $\mathrm{NH}_{2}$ groups in the film.

\subsection{Atmospheric pressure Matrix Assisted Light Desorption Ionisation (MALDI) ORBITRAP Mass spectrometry}

In light of information as to the atomic composition and molecular structure determined by XPS and FTIR measurements, and in order to have a better description of the molecular structure of the produced thin films, mass spectrometry measurements were carried out. The focus is made on thin films that exhibit a high organic content, that is, those synthesized with $t_{\text {on }}=50$ and $t_{\text {off }}=200 \mathrm{~ms}$.

Measurements were done using an Atmospheric Pressure (AP) Matrix Assisted Light Desorption Ionisation (MALDI) mass spectrometry measurements using ORBITRAP analyzer to reach a high resolution in mass measurements. Mass spectrometry measurement on highly reticulated silica-based thin films is a rather tricky task. Indeed, because of the very high energy of the $\mathrm{Si}-\mathrm{O}$ bonding (around $5 \mathrm{eV}$ ), it is challenging to get proper spectra for it is very difficult to break these bonds. Thus, MALDI ORBITRAP was chosen, in order to enhance ionization of the molecular fragments. A pp-APTES thin film was deposited on a silicon wafer priory coated by a dihydroxybenzoic acid layer. Then, a laser was focused on the thin film in order to desorb molecular groups. Figure 11 presents the mass spectrum obtained from a pp-APTES deposited with the experimental parameters chosen to get highly organic structure.

Interesting information can be obtained by carefully looking at this mass spectrum. First, one can see different groups of peaks with similar repeatability. These groups are framed in red on the spectrum. These groups of peaks are separated by a mass difference of $\Delta m=119.04028$ (red arrows in Figure 11) which exactly corresponds to the mass of one $\mathrm{C}_{3} \mathrm{H}_{9} \mathrm{NO}_{2} \mathrm{Si}$ group. This unambiguous identification is possible thanks to the resolution provided by the OBITRAP instrument. Thus, these groups correspond to oligomers of $\mathrm{C}_{3} \mathrm{H}_{9} \mathrm{NO}_{2} \mathrm{Si}$ monomers. This monomer corresponds exactly to a part of the APTES molecule, including the $\mathrm{Si}$ atom and an intact aminopropyl chain. These groups are thus APTES fragments that are cross-linked by means of two initial ethoxy chains while conserving intact aminopropyl chains. The last ethoxy chain is replaced by an $\mathrm{OH}$ group immediately bonded to 
the $\mathrm{Si}$ atom. One can see different groups of oligomers composed of $\mathrm{x}$ monomer units with $\mathrm{x}$ ranging from 3 to 8 base units. These oligomers are referenced in the spectrum as " $\mathrm{Si}_{\mathrm{x}}$."

The second point of interest can be observed in an oligomeric group of peaks. In one group, several peaks are separated by a mass difference $\Delta m=18$. These peaks are denoted in the spectrum by green arrows between them. This mass difference corresponds to the loss of an $\mathrm{H}_{2} \mathrm{O}$ molecule. This can be interpreted as a cross-linking reaction following the reaction $\mathrm{SiOH}+\mathrm{SiOH}$ à $\mathrm{Si}-\mathrm{O}-\mathrm{Si}+\mathrm{H}_{2} \mathrm{O}$. The difference between 2 peaks in a same " $\mathrm{Si}_{\mathrm{x}}$ " group with a mass difference of 18 , could thus correspond to a higher cross-linking, as summarized in Figure 12.

Thus, various oligomers composed of $\mathrm{C}_{3} \mathrm{H}_{9} \mathrm{NO}_{2} \mathrm{Si}$ monomers can be detected.

The final information further brought by this spectrum emphasizes this point. In the highest mass range of the spectrum, one can detect peaks that can be unambiguously identified as silsesquioxanes (cages) and cyclosiloxanes (rings) oligomers APTES monomers. These peaks are arrowed in blue in the spectrum. The spectrum points out peaks at mass corresponding to $\left[\mathrm{C}_{12} \mathrm{H}_{34} \mathrm{~N}_{4} \mathrm{Si}_{4} \mathrm{O}_{7}+\mathrm{H}\right]+$ ion $(\mathrm{m} / \mathrm{z}=459.15774 ; \Delta m=0.28 \mathrm{ppm})$, $\left[\mathrm{C}_{21} \mathrm{H}_{59} \mathrm{~N}_{7} \mathrm{Si}_{7} \mathrm{O}_{12}+\mathrm{H}\right]+$ ion $(m / z=798.26793 ; \Delta m=0.36 \mathrm{ppm})$ and $\left[\mathrm{C}_{24} \mathrm{H}_{64} \mathrm{~N}_{8} \mathrm{Si}_{8} \mathrm{O}_{12}+\mathrm{H}\right]+$ ion $(m / z=881.28706 ; \Delta m=0.27 \mathrm{ppm})$. These structures are represented in Figure 13.

Even if the identification of these complex structures is certain, these results stay qualitative. Indeed, the MALDIORBITRAP technique used do not allow getting an estimation of the cyclosiloxanes and silsesquioxanes density embedded into the film. Nevertheless, this quantity can be adjusted by playing on the ton and toff. Indeed, the presence of it is directly linked to the pulse mode of the remote plasma and analyses (not shown here) made on deposited samples in continuous mode, do not have any similar structures. Also, according to FTIR results, the incorporation of organic moieties and $-\mathrm{NH}_{2}$ groups in the film is adjusted by tuning the ton/toff ratio; that is, short ton and long toff will favor the production of cyclosiloxanes and silsesquioxanes. Hence, adjusting the ton and toff time of a pulsed postdischarge PECVD process could thus constitute a convenient and elegant manner to tune the density of polysilsesquioxanes in as-grown plasma polymer layers.

Polysilsesquioxanes have provoked an increasing interest in the last decades because of their unique property as ring or cage molecules and because of their stability.[69,70] It has been proposed and proved that it can play an important role as cage molecule, in the field of nanomedicine for example, in order to convey a drug in a specific organ without being degraded. This kind of ring and or cage molecule based on SiOCH chemistry might also be 
used in microelectronics, where the incorporation of nanoporosity can decrease the dielectric constant, which is major interest in Ultra low-k material production.

As far as we know, this is the first time that the production of polysilsesquioxanes is reported using a plasma process. These molecules are usually obtained by complex reactions using wet chemistry, and they require high volumes of solvent and reactive.[71] The possibility to produce that kind of structures, as well as to integrate it in a more inorganic and dense matrix in a same process with a sole precursor could thus be of very high interest for practical applications. Indeed, the embedment of cyclosiloxane and silsesquioxanes into the film is likely to increase the porosity and reduce the density of the film. Several physical properties such as the refractive index and the dielectric constant $\mathrm{k}$ would thus be lowered with the incorporation of such structures. Furthermore, the presence of intact aminopropyl chains in the pp-APTES would likely increase the adhesion properties of the film as $-\mathrm{NH}_{2}$ are known to play a major role in chemical adhesion mechanisms. Finally, these amino rich structures could be of major interest to covalently immobilize biomolecules. The pulsed remote plasma polymerised APTES thin films presented in our manuscript could thus present highly interesting potentialities for applications in the field of adhesion, low-k material for electronics, and biocompatible functional thin films.

\section{CONCLUSION}

In this work, it has been shown that pulsing a remote PACVD process allow to tune on a wide scale the thin film composition and its molecular structure. In particular, the use of medium ton (tens of ms) and long $t_{\text {off }}$ (hundreds of $\mathrm{ms}$ ), allows to enhance the initial monomer structure retention into the growing film. These benefits result mainly from two different mechanisms which have been highlighted: first, short substrate exposure (short $t_{o n}$ ) to remote plasma during a pulse cycle is enough to initiate the coating growth and reduces the chemical etching of thin film organic parts. Secondly, long plasma off duration (long $t_{\text {off }}$ ) favors the deposition of APTES radical fragments that undergoes mild or low degradation and APTES oligomers. Hence, highly organic thin films can be deposited in these conditions.

Furthermore, thin film mass spectrometry measurements have pointed out the synthesis of various oligomers based on APTES with complete and intact aminopropyl chain. Oligomers containing up to eight APTES derived monomers $\left(\mathrm{C}_{3} \mathrm{H}_{9} \mathrm{NO}_{2} \mathrm{Si}\right)$ and eight primary amine groups were undoubtedly detected. Among them, silsesquioxanes (cages) and cyclosiloxanes (rings) have been clearly identified. The production of such inorganic-organic molecules using a plasma process is reported in this work for the first time. This "pulsed 
remote plasma assisted chemical vapor deposition process" described here with the APTES monomer can be adapted to other precursors. Hence, it could be an interesting alternative as a soft process for the synthesis of complex molecules that requires the preservation of weak chemical functions. The potentialities offered by this "pulsed remote plasma" process could thus be promising to synthesize thin films with interesting properties in the field of low-k material, adhesion, or biomolecule immobilization.

\section{ACKNOWLEDGEMENTS}

This research was carried out in the framework of the METABIO project funded by the Luxembourgish agency "Fonds National de la Recherche" (INTER/MAT/13/13) and within the framework of the Laboratoire Européen Associé LIPES, a structure supported by the CNRS to whom we convey our deepest gratitude. 


\section{REFERENCES}

[1] G. Camporeale, M. Moreno-Couranjou, S. Bonot, R. Mauchauffé, N. D. Boscher, C. Bebrone, C. Van De Weerdt, H. M. Cauchie, P. Favia, P. Choquet, Plasma Process. Polym. 2015, 12, 1208-1219.

[2] S. Bonot, R. Mauchauffé, N. D. Boscher, M. Moreno-Couranjou, H. M. Cauchie, P. Choquet, Adv. Mater. Interfaces 2015, 2, 1-11.

[3] F. Taraballi, S. Zanini, C. Lupo, S. Panseri, C. Cunha, C. Riccardi, M. Marcacci, M. Campione, J. Colloid Interface Sci. 2013, 394, 590-597.

[4] R. Mauchauffé, M. Moreno-Couranjou, N. D. Boscher, C. Van De Weerdt, A.-S. Duwez, P. Choquet, J. Mater. Chem. B. 2014, 2, 5168-5177.

[5] J. N. Borges, T. Belmonte, J. Guillot, D. Duday, M. Moreno-Couranjou, P. Choquet, H. N. Migeon, Plasma Process. Polym. 2009, 6, 490-495.

[6] C. Tarducci, W. C. E. Schofield, J. P. S. Badyal, S. A. Brewer, C. Willis, Chem. Mater. 2002, 2541-2545.

[7] C. Klages, K. Höpfner, N. Kläke, R. Thyen, Plasma Polym. 2000, 5, 79-89.

[8] M. Minier, M. Salmain, N. Yacoubi, L. Barbes, C. Méthivier, S. Zanna, C. Pradier, Langmuir 2005, 5957-5965.

[9] R. Bogdanowicz, M. Sawczak, P. Niedzialkowski, P. Zieba, B. Finke, J. Ryl, J. Karczewski, T. Ossowski, J. Phys. Chem. C. 2014, 118, 8014-8025.

[10] E. S. Carlisle, M. R. Mariappan, K. D. Nelson, B. E. Thomes, R. B. Timmons, A. Constantinescu, R. C. Eberhart, P. E. Bankey, Tissue Eng. 2000, 6, 45-52.

[11] C. Volcke, R. P. Gandhiraman, V. Gubala, J. Raj, T. Cummins, G. Fonder, R. I. Nooney, Z. Mekhalif, G. Herzog, S. Daniels, D. W. M. Arrigan, A. A. Cafolla, D. E. Williams, Biosens. Bioelectron. 2010, 25, 1875-1880.

[12] Z. Yang, J. Wang, R. Luo, M. F. Maitz, F. Jing, H. Sun, N. Huang, Biomaterials 2010, 31, 2072-2083.

[13] S. B. Hartono, S. Z. Qiao, K. Jack, B. P. Ladewig, Z. Hao, G. Q. Lu, Langmuir. 2009, $25,6413-6424$.

[14] S. J. Oh, S. J. Cho, C. O. Kim, J. W. Park, Langmuir 2002, 18, 1764-1769.

[15] Q. Chen, R. Förch, W. Knoll, Chem. Mater. 2004, 16, 614-620.

[16] A. Simon, T. Cohen-Bouhacina, M. C. Porté, J. P. Aimé, C. Baquey, J. Colloid Interface Sci. 2002, 251, 278-283.

[17] P. Hamerli, T. Weigel, T. Groth, D. Paul, Biomaterials 2003, 24, 3989-3999.

[18] D. A. Puleo, R. A. Kissling, M. S. Sheu, Biomaterials 2002, 23, 2079-2087. 
[19] G. Aziz, N. De Geyter, H. Declercq, R. Cornelissen, R. Morent, Surf. Coatings Technol. $2015,271,39-47$.

[20] A. Choukourov, H. Biederman, D. Slavinska, L. Hanley, A. Grinevich, H. Boldyryeva, A. Mackova, J. Phys. Chem. B. 2005, 109, 23086-23095.

[21] A. Choukourov, H. Biederman, D. Slavinska, M. Trchova, A. Hollander, Surf. Coatings Technol. 2003, 174-175, 863-866.

[22] X. J. Dai, J. Du Plessis, I. L. Kyratzis, G. Maurdev, M. G. Huson, C. Coombs, Plasma Process. Polym 2009, 6, 490-497.

[23] L. Denis, D. Cossement, T. Godfroid, F. Renaux, C. Bittencourt, R. Snyders, M. Hecq, Plasma Process. Polym. 2009, 6, 199-208.

[24] B. Finke,K. Schröder,A.Ohl, Plasma Process. Polym. 2009, 6, 70-74.

[25] J. Friedrich, R. Mix, G. Kühn, I. Retzko, A. Schönhals, W. Unger, Compos. Interfaces 2003, 10, 173-223.

[26] J. F. Friedrich, R. Mix, G. Kühn, Surf. Coatings Technol. 2003, 174-175, 811-815.

[27] J. Friedrich, G. Kühn, R. Mix, A. Fritz, A. Schönhals, J. Adhes. Sci. Technol. 2003, 17, 1591-1617.

[28] R. P. Gandhiraman, V. Gubala, L. C. H. Nam, C. Volcke, C. Doyle, B. James, S. Daniels, D. E. Williams, Colloids Surfaces B Biointerfaces 2010, 79, 270-275.

[29] A. Harsch, J. Calderon, R. B. Timmons, G. W. Gross, J. Neurosci. Methods 2000, 98, $135-144$.

[30] A. Manakhov, L. Zajíčková, M. Eliáš, J. Čechal, J. Polčák, J. Hnilica, Š. Bittnerová, D. Nečas, Plasma Process. Polym. 2014, 11, 532-544.

[31] S. Ben Said, F. Arefi-Khonsari, J. Pulpytel, Plasma Process. Polym. 2016, 13, 10251035 .

[32] C. Volcke, R. P. Gandhiraman, V. Gubala, C. Doyle, G. Fonder, P. A. Thiry, A. A. Cafolla, B. James, D. E. Williams, J. Colloid Interface Sci. 2010, 348, 322-328.

[33] Z. Yang, X. Wang, J. Wang, Y. Yao, H. Sun, N. Huang, Plasma Process. Polym. 2009, $6,498-505$.

[34] J. Friedrich, The Plasma Chemistry of Polymer Surfaces: Advanced Techniques for Surface Design, Wiley-VCH Verlag GmbH \& Co, KGaA 2012.

[35] E. Lecoq, D. Duday, S. Bulou, G. Frache, F. Hilt, R. Maurau, P. Choquet, Plasma Process. Polym. 2013, 10, 250-261.

[36] R. Peña-Alonso, F. Rubio, J. Rubio, J. L. Oteo, J. Mater. Sci. 2007, 42, 595-603.

[37] M. Zhu, M. Z. Lerum, W. Chen, Langmuir 2012, 28, 416-423. 
[38] J. Kim, P. Seidler, L. S. Wan, C. Fill, J. Colloid Interface Sci. 2009, 329, 114-119.

[39] V. Gubala, R. P. Gandhiraman, C. Volcke, C. Doyle, C. Coyle, B. James, S. Daniels, D. E. Williams, Analyst 2010, 135, 1375.

[40] R. P. Gandhiraman, C. Volcke, V. Gubala, C. Doyle, L. Basabe- Desmonts, C. Dotzler, M. F. Toney, M. Iacono, R. I. Nooney, S. Daniels, B. James, D. E. Williams, J. Mater. Chem. 2010, 20, 4116.

[41] F. Loyer, N. D. Boscher, G. Bengasi, G. Frache, P. Choquet, Plasma Process. Polym. $2018,15,1-11$.

[42] F. Loyer, G. Frache, P. Choquet, N. D. Boscher, Macromolecules 2017, 50, 4351-4362.

[43] I. Blaszczyk-Lezak, A. M. Wrobel, M. P. M. Kivitorma, I. J. Vayrynen, T. Aoki, Diam. Relat. Mater. 2006, 15, 1484-1491.

[44] I. Blaszczyk-Lezak, A. M. Wrobel, Appl. Surf. Sci. 2007, 253, 7404-7411.

[45] M.Gueye, T. Gries, C.Noël, S.Migot-Choux, S. Bulou, E. Lecoq, P. Choquet, T. Belmonte, Plasma Process. Polym. 2016, 13, 698-710.

[46] G. Lucovsky, D. V. Tsu, J. Vac. Sci. Technol. A Vacuum, Surfaces, Film. 1987, 5, 2231-2238.

[47] L. G. Meiners, J. Vac. Sci. Technol. 1982, 21, 655.

[48] H. Nedelmann, T. Weigel, H. G. Hicke, J. Müller, D. Paul, Surf. Coatings Technol. 1999, 116-119, 973-980.

[49] M. Schiller,W. Kulisch, Surf. Coatings Technol. 1998, 98, 1590-1599.

[50] M. Gueye, T. Gries, C. Noel, S. Migot-Choux, S. Bulou, E. Lecoq, P. Choquet, K. Kutasi, T. Belmonte, Plasma Chem. Plasma Process. 2016, 36, 1031.

[51] H. G. P. Lewis, D. J. Edell, K. K. Gleason, Chem. Mater. 2000, 12, 3488-3494.

[52] D. Bhattacharyya, K. Pillai, O. M. R. Chyan, L. Tang, R. B. Timmons, Chem. Mater. 2007, 19, 2222-2228.

[53] G. Mishra, S. L. McArthur, Langmuir 2010, 26, 9645-9658.

[54] Q. Wu, K. K. Gleason, Plasmas Polym. 2003, 8, 31-41.

[55] A. Francescangeli, F. Palumbo, R. d'Agostino, C. Defranoux, Plasma Process. Polym. 2009, 6, 132-138.

[56] J. F. Friedrich, I. Retzko, G. Kühn, W. E. S. Unger, A. Lippitz, Surf. Coatings Technol. 2001, 142-144, 460-467.

[57] J. Friedrich, Plasma Process. Polym. 2011, 8, 783-802.

[58] A. Manakhov, M. Moreno-Couranjou, N. D. Boscher, V. Rogé, P. Choquet, J. J. Pireaux, Plasma Process. Polym. 2012, 9, 435-445. 
[59] L. Denis, P. Marsal,Y. Olivier, T. Godfroid, R. Lazzaroni,M. Hecq, J. Cornil, R. Snyders, Plasma Process. Polym. 2010, 7, 172-181.

[60] Z. Zhang, Q. Chen, W. Knoll, R. Foerch, R. Holcomb, D. Roitman, Macromolecules 2003, 36, 7689-7694.

[61] F. Neese, WIREs Comput. Mol. Sci. 2017, e1327, 1-6.

[62] F. Weigend, R. Ahlrichs, Phys. Chem. Chem. Phys. 2005, 7, 3297-3305.

[63] F. Weigend, Phys. Chem. Chem. Phys. 2006, 8, 1057-1065.

[64] S. Grimme, S. Ehrlich, L. Goerigk, J. Comput. Chem. 2011, 32, 1456-1465.

[65] S. Grimme, J. Antony, S. Ehrlich, H. Krieg, S. Grimme, J. Antony, S. Ehrlich, H. Krieg, J. Chem. Phys. 2010, 132.

[66] H. Kruse, S. Grimme, J. Chem. Phys. 2012, 136.

[67] A. Bousquet, A. Granier, A. Goullet, J. P. Landesman, Thin Solid Films 2006, 514, 4551.

[68] A. Bousquet, V. Bursikova, A. Goullet, A. Djouadi, L. Zajickova, A. Granier, Surf. Coatings Technol. 2006, 200, 6517-6521.

[69] D. A. Loyt, K. J. Shea, Chem. Rev. 1995, 99, 1431-1442.

[70] K. J. Shea, D. A. Loy, Chem. Mater. 2001, 13, 3306-3319.

[71] J. Zeschky, T. Höfner, C. Arnold, R. Weißmann, D. Bahloul- Hourlier, M. Scheffler, P. Greil, Acta Mater. 2005, 53, 927-937. 


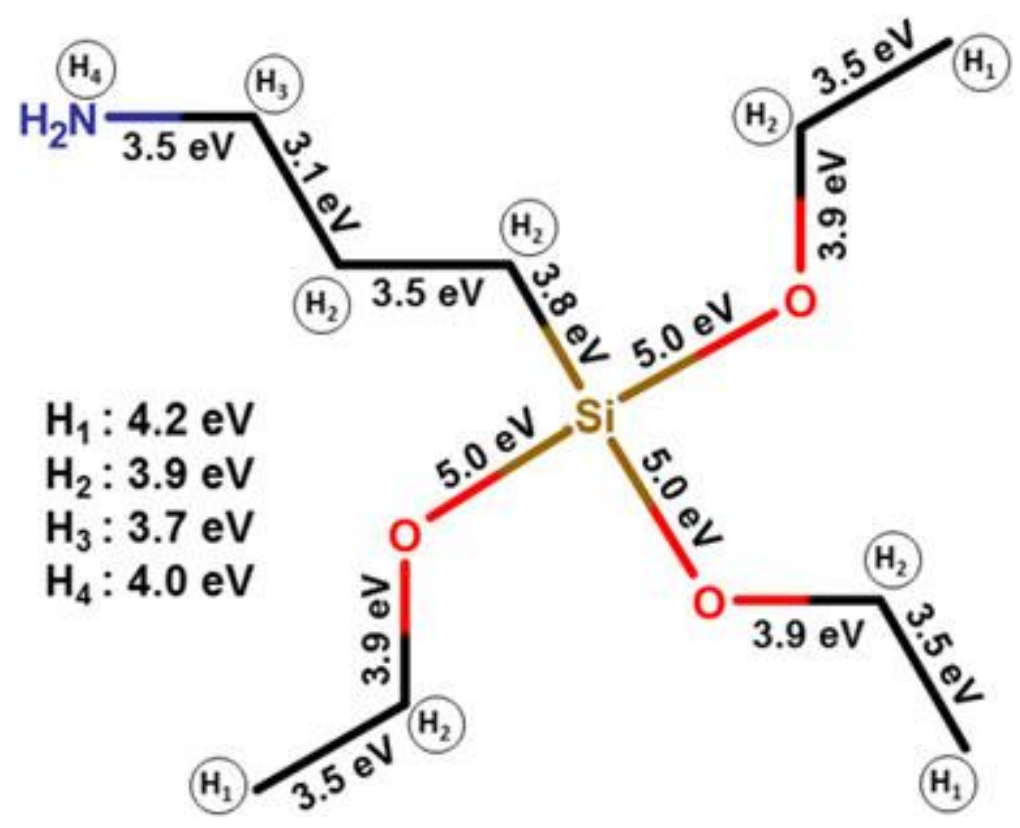

Figure 1: Bond dissociation energies of the APTES monomer determined by density functional theory calculation. 


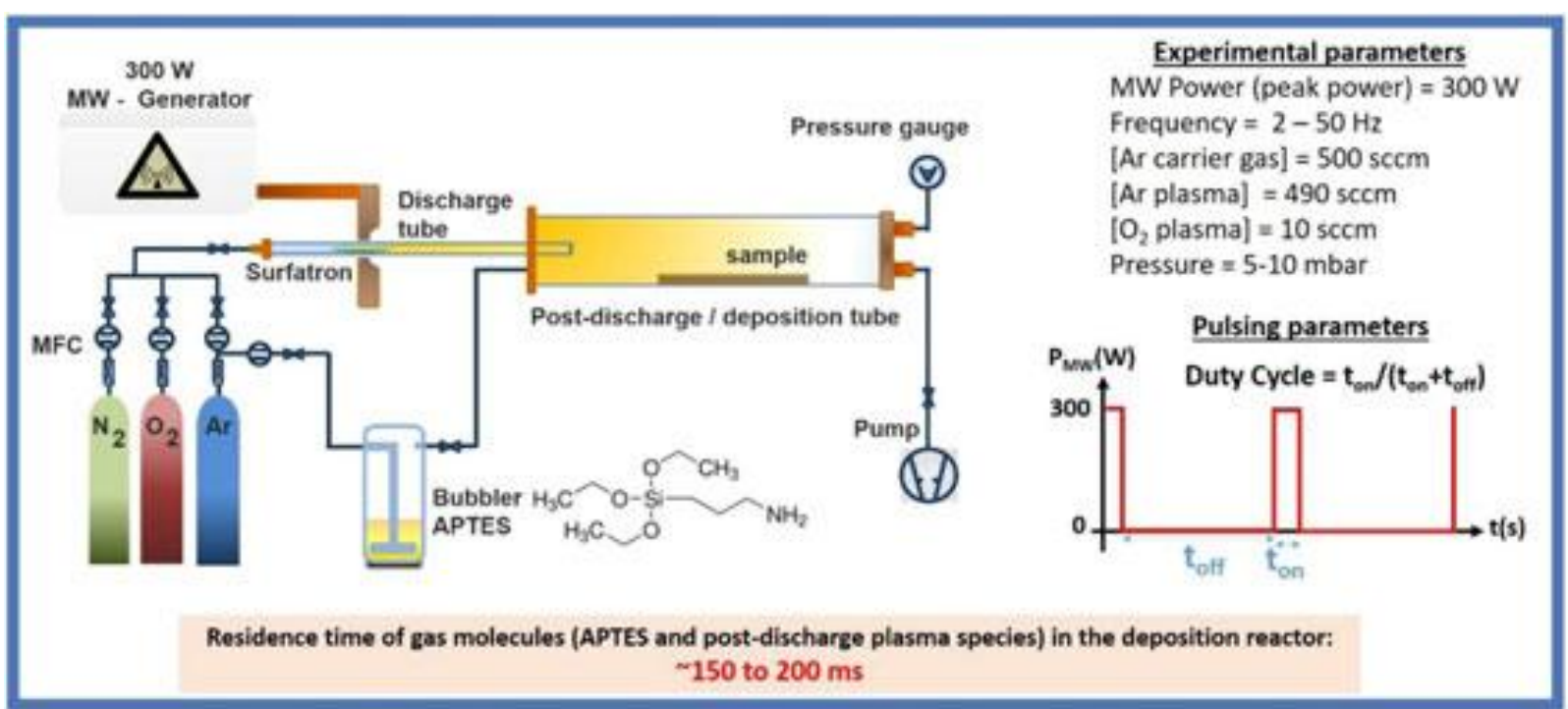

Figure 2 : Experimental setup. 


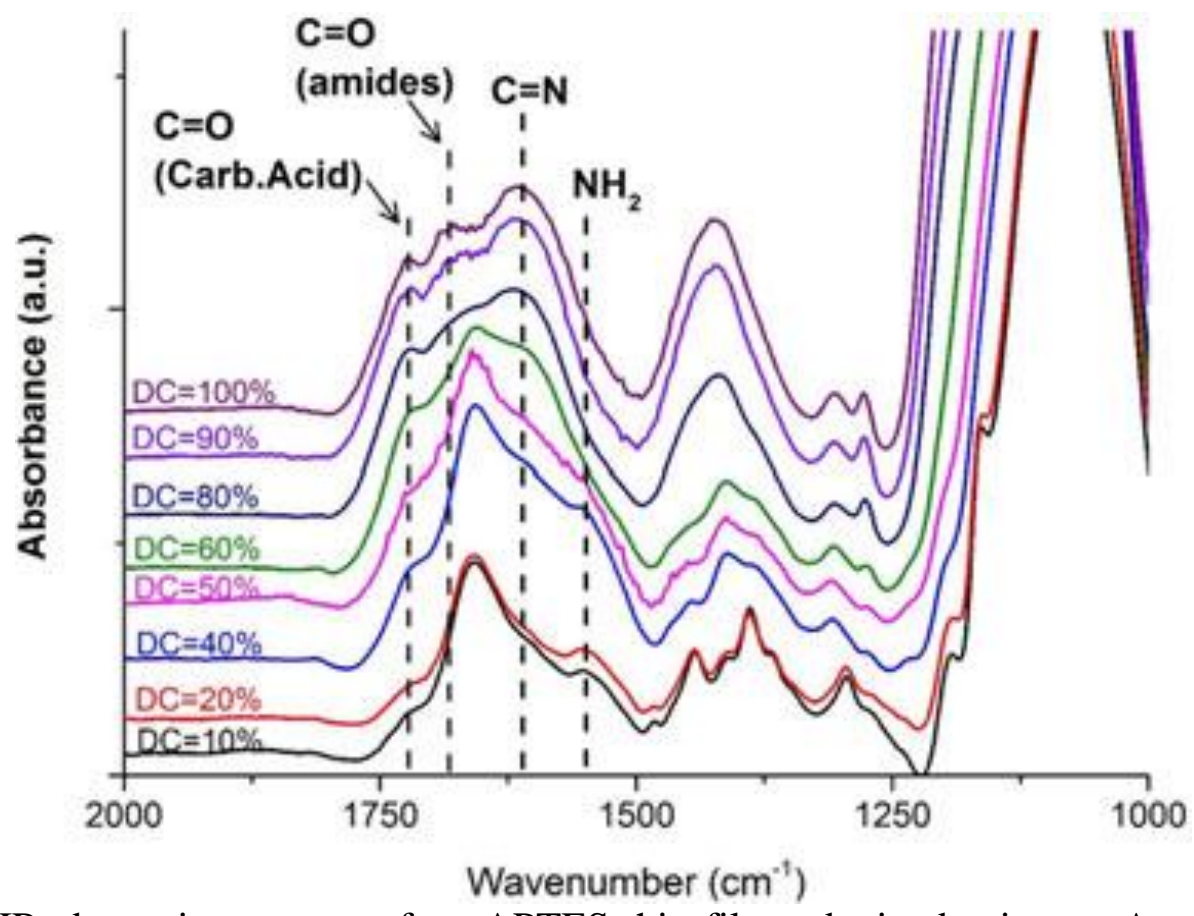

Figure 3: IR absorption spectra of pp-APTES thin films obtained using an $\mathrm{Ar}-\mathrm{O}_{2}$ plasma operated at $10 \mathrm{~Hz}$ and for different duty cycles from $100 \%$ (continuous plasma) to $10 \%$ (ton = $10 \mathrm{~ms}$; toff $=90 \mathrm{~ms}$ ). 


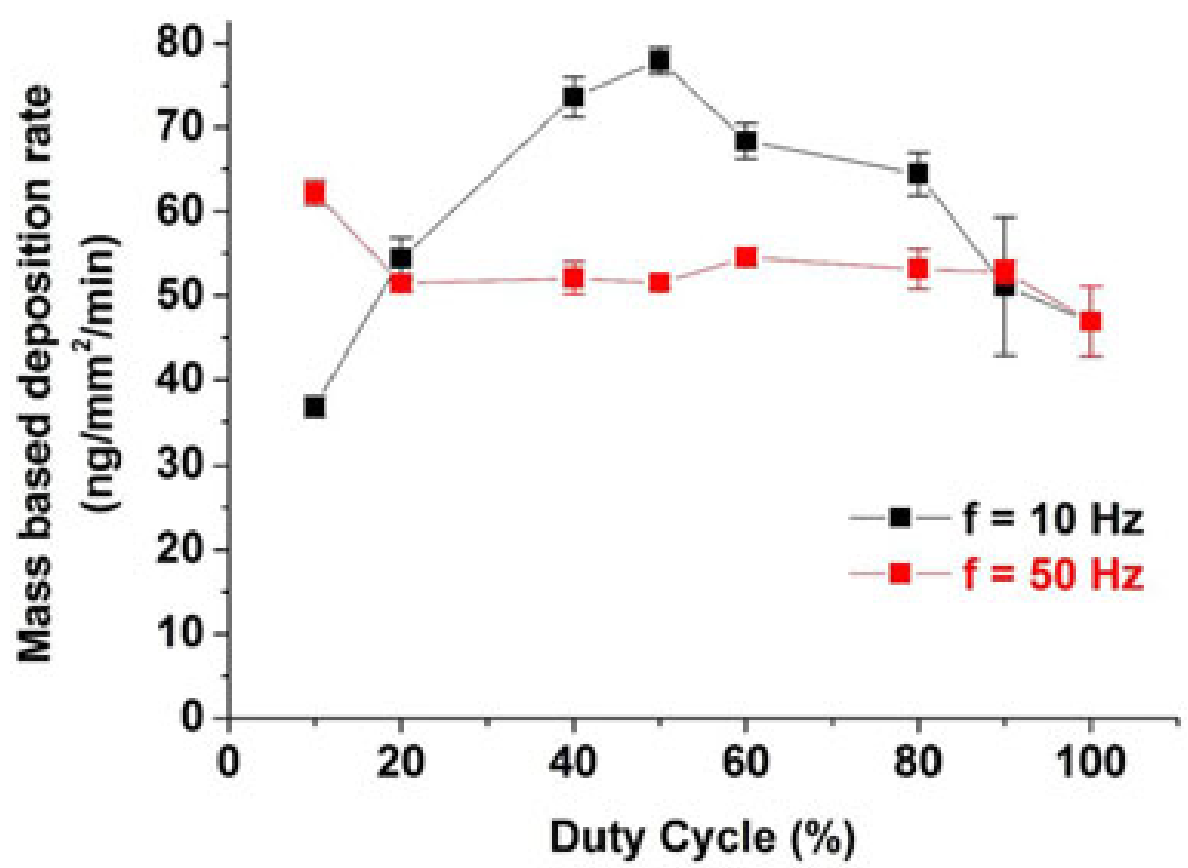

Figure 4: Deposition rate as determined from mass variation measurements vs duty cycle at 2 frequencies: $10 \mathrm{~Hz}$ and $50 \mathrm{~Hz}$. 


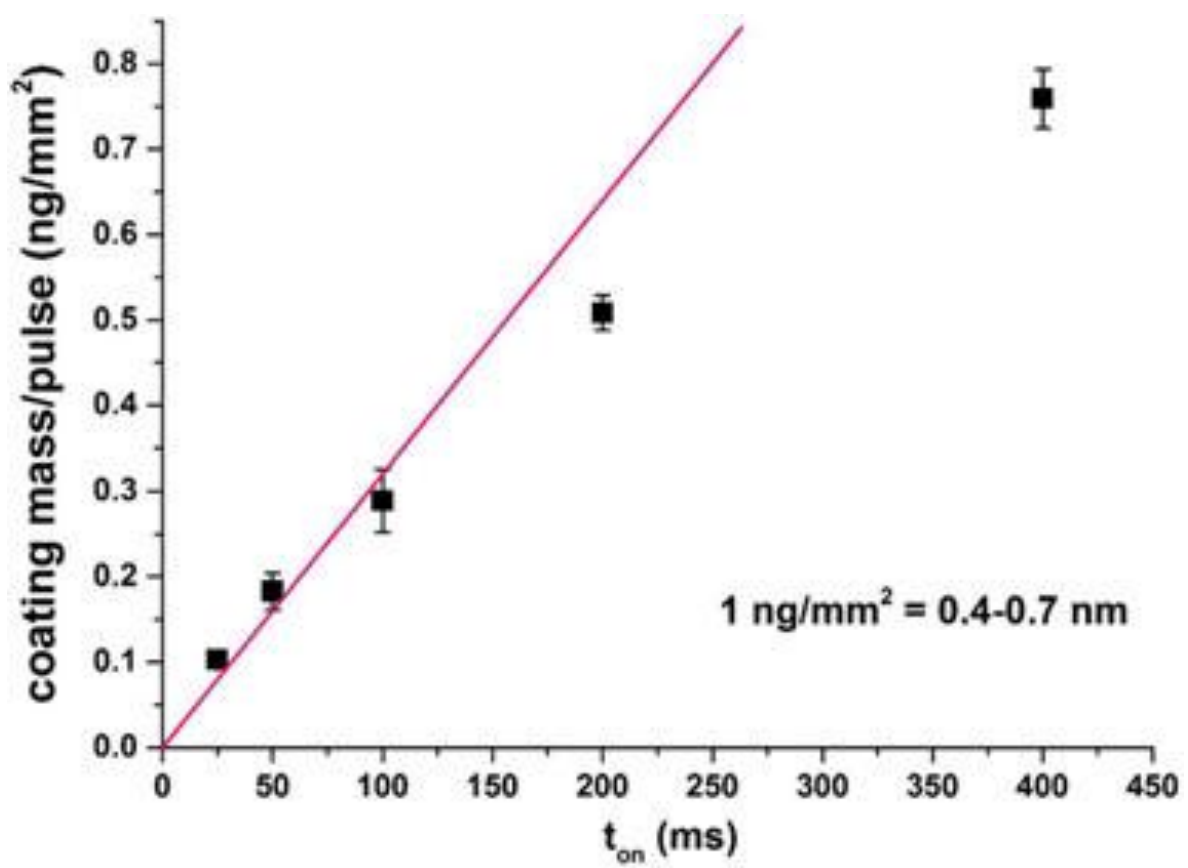

Figure 5: Deposited mass per pulse of plasma as a function of $t_{\text {on }}$ and for a constant $t_{\text {off }}$ equal to $200 \mathrm{~ms}$ 


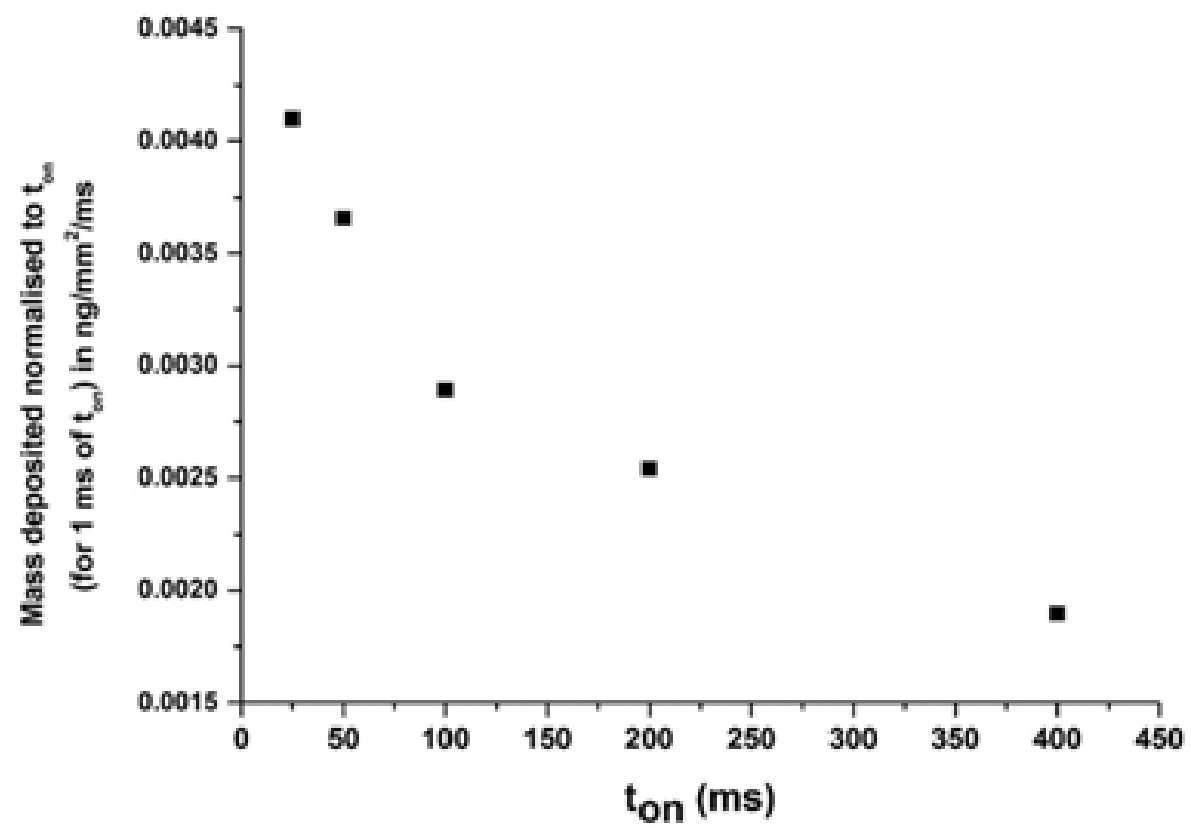

Figure 6: Average deposition rates (mass deposited per unit area and divided by $t_{o n}$ ) as a function of $t_{\text {on }}$ from 25 to $400 \mathrm{~ms}\left(t_{\text {off }}=200 \mathrm{~ms}\right)$ 

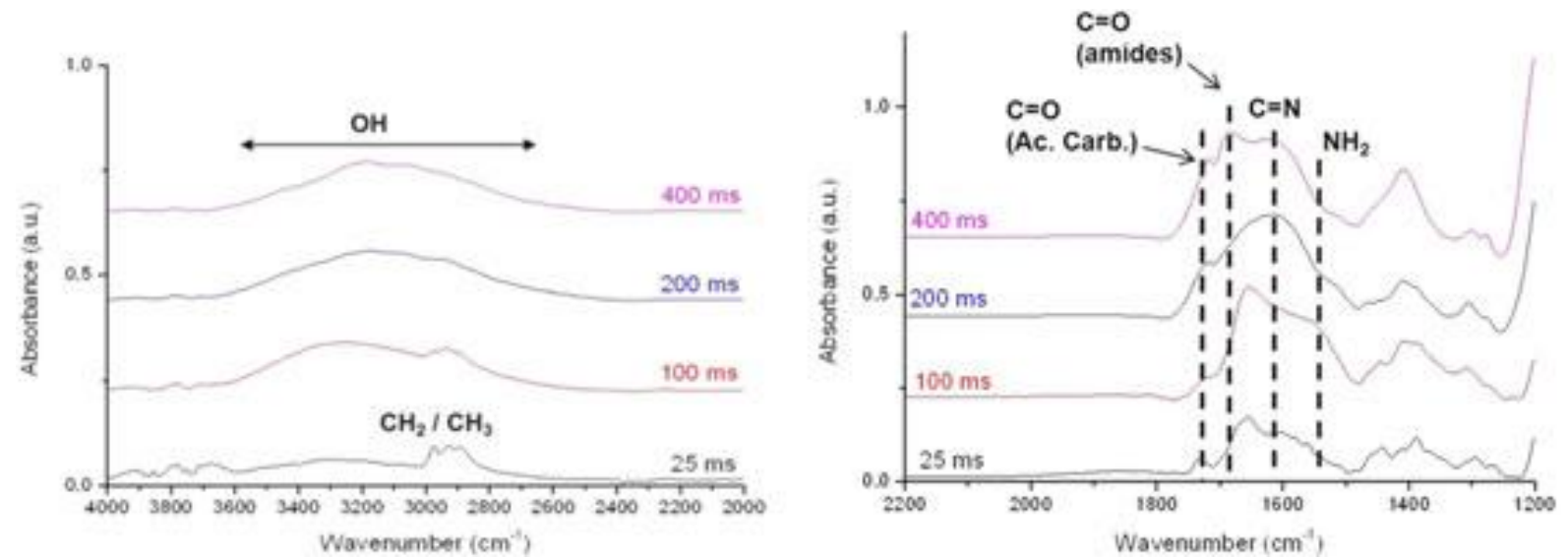

Figure 7: FTIR spectra for deposition with $t_{o n}=25,100,200$, and $400 \mathrm{~ms}$, in the range 2000$4000 \mathrm{~cm}^{-1}$ (left) and $1200-2200 \mathrm{~cm}^{-1}$ (right) 


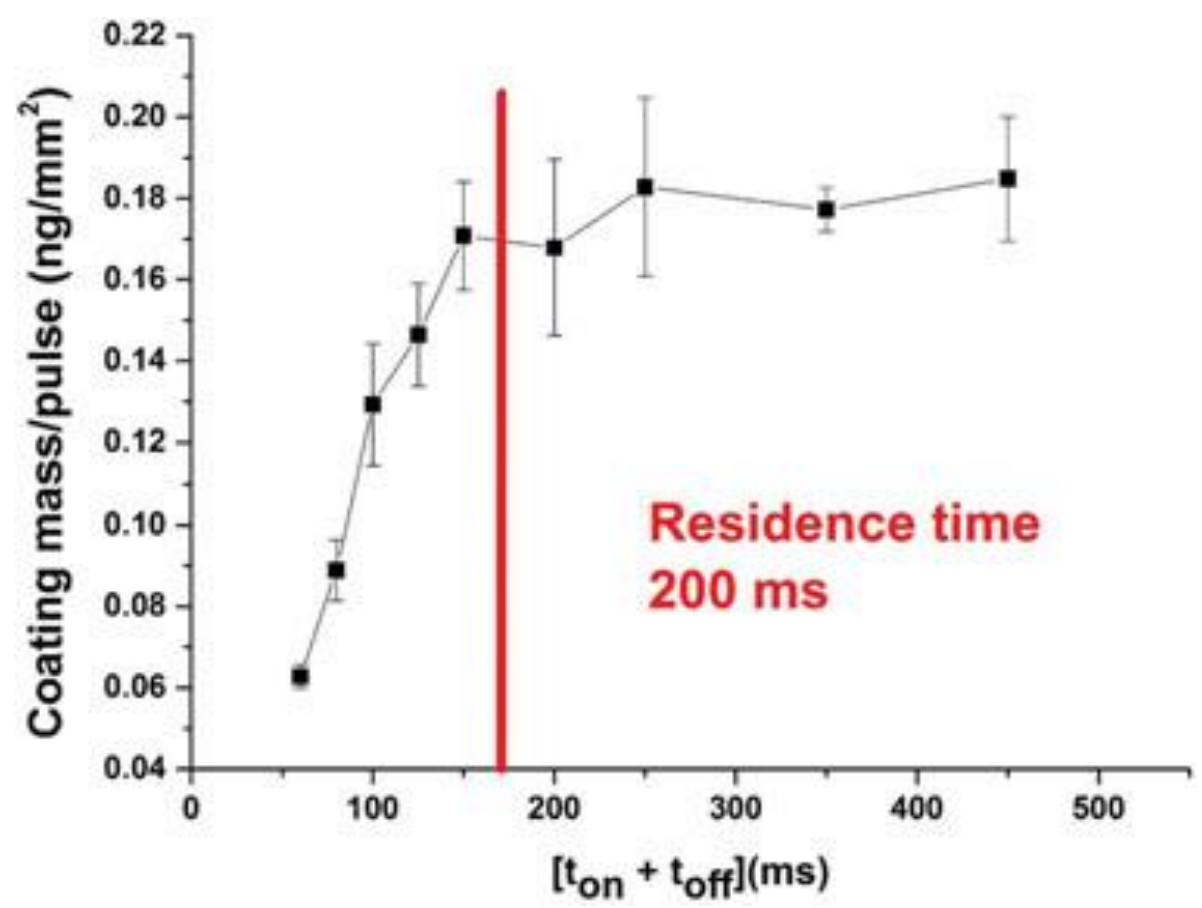

Figure 8: Deposited mass per pulse as a function of $t_{o n}+t_{o f f}\left(t_{o n}=50 \mathrm{~ms}\right)$ for $t_{\text {off }}$ between 10 $\mathrm{ms}$ and $400 \mathrm{~ms}$ 


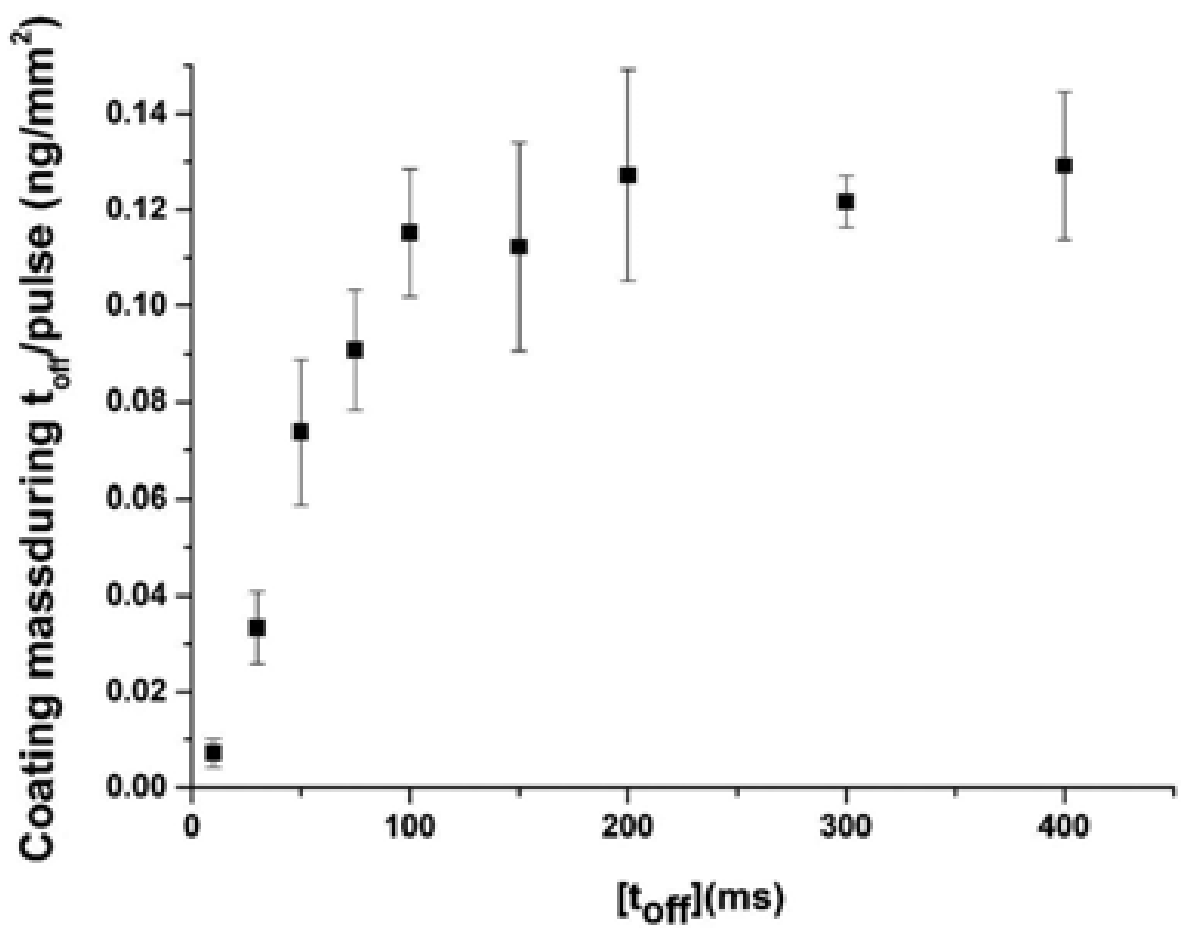

Figure 9: Coating mass deposited per pulse during $t_{\text {off }}$ as a function of $t_{\text {off }}$ for $t_{\text {off }}$ between 10 and $400 \mathrm{~ms}$ 

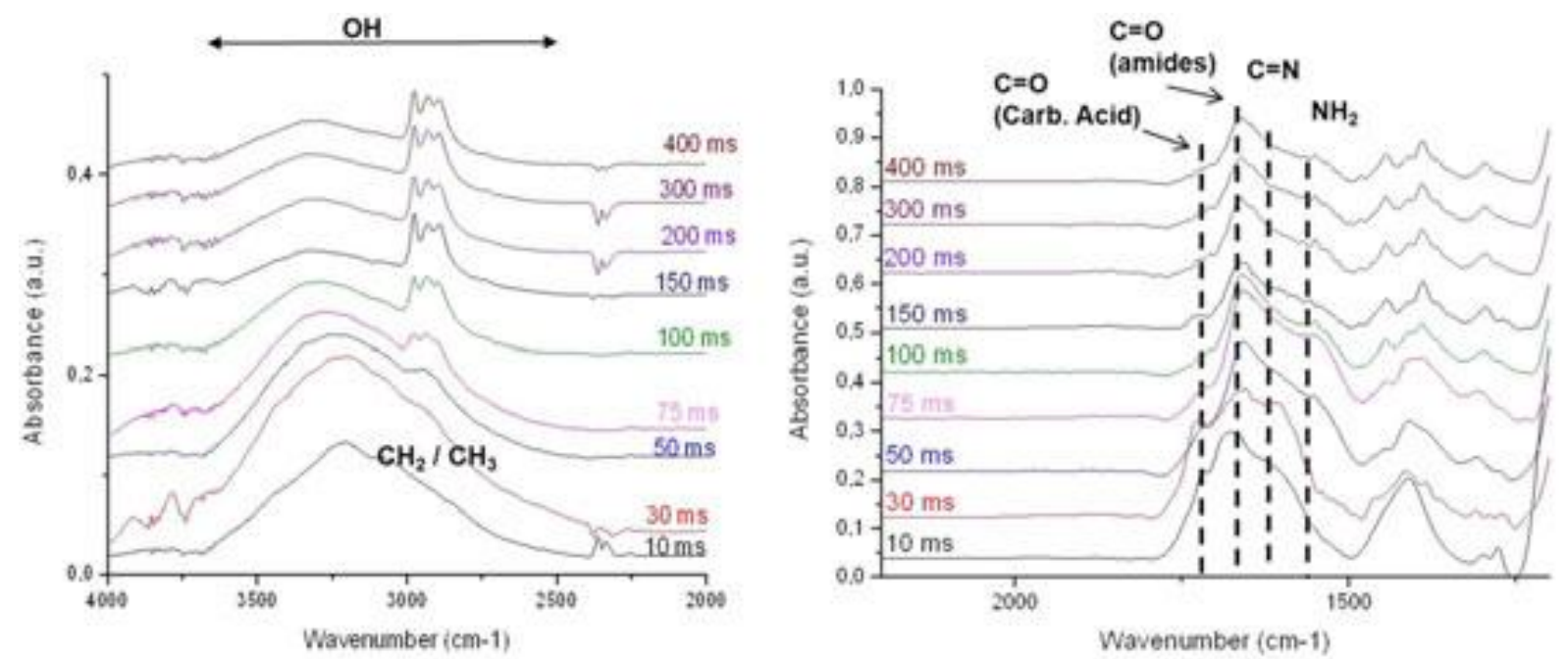

Figure 10: FTIR spectra for deposition with $t_{\text {off }}=10,30,50,75,100,150,200,300$, and 400 $\mathrm{ms}$, in the range $2000-4000 \mathrm{~cm}^{-1}$ (left) and $1200-2200 \mathrm{~cm}^{-1}$ (right) 


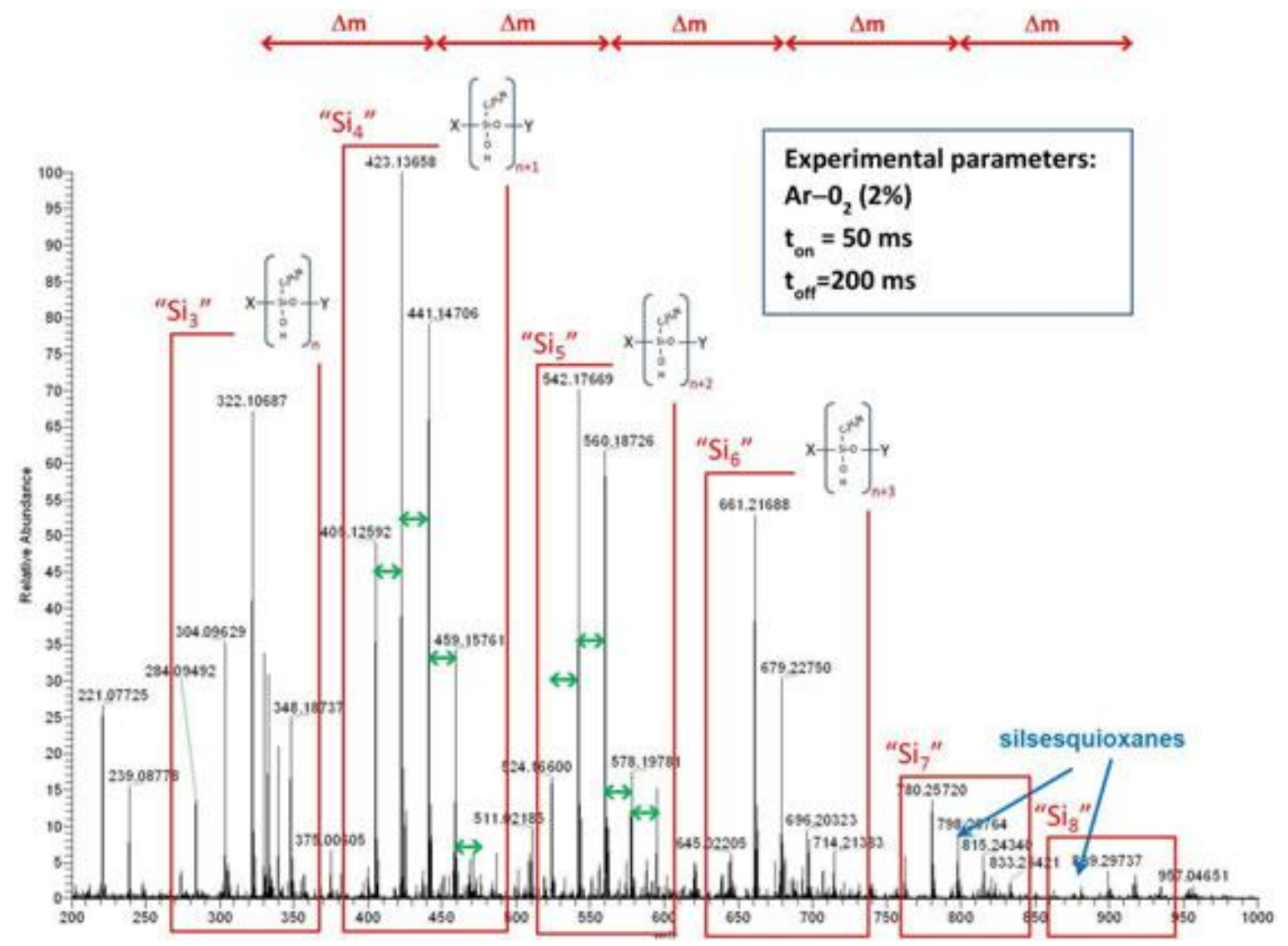

Figure 11: Atmospheric Pressure Matrix Assisted Laser Desorption Ionisation - ORBITRAP spectrum of a pp-APTES thin film deposited on a silicon wafer priory coated by a dihydroxybenzoic acid layer 

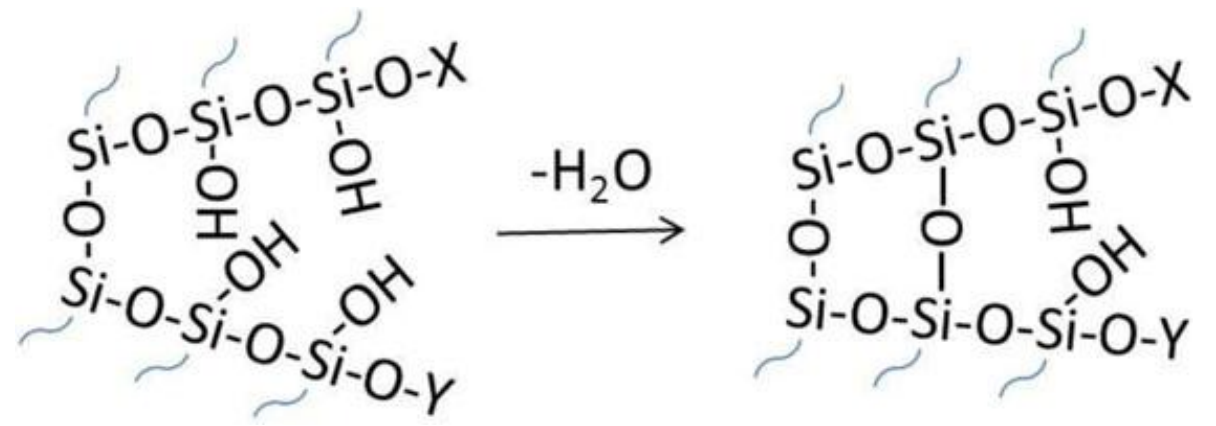

Figure 12: Illustration of a crosslinking reaction between two $\mathrm{OH}$ groups in an oligomeric group leading to the loss $\Delta m=18$ and the removal of a $\mathrm{H}_{2} \mathrm{O}$ molecule 
<smiles>CCCC[Si]1(O)O[Si](O)(CCCN)O[Si](O)(CCCN)O[Si]2(CCCN2)O[Si](O)(CCN)O1</smiles><smiles>[R][Si]1(O)O[Si]([R])(O)O[Si]2([R])O[Si]3([R])O[Si]([R])(O2)O[Si]2([R])O[Si]([R])(O1)O[Si]([R])(O2)O3</smiles><smiles>NCCC[Si]12O[Si]3(CCCN)O[Si]4(CCCN)O[Si](CCCN)(O1)O[Si]1(CCCN)O[Si](CCCN)(O2)O[Si](CCCN)(O3)O[Si](CCCN)(O4)O1</smiles>

Figure 13: Representation of silsesquioxanes (cages) and cyclosiloxanes (rings) oligomers made of APTES monomers deduced from Atmospheric Pressure Matrix Assisted Laser Desorption Ionisation - ORBITRAP spectra 